\title{
Functional level at admission is a predictor of survival in older patients admitted to an acute geriatric unit
}

Lars E Matzen ${ }^{1,2^{*}}$, Ditte B Jepsen², Jesper Ryg ${ }^{1,2}$ and Tahir Masud ${ }^{2,3}$

\begin{abstract}
Background: Functional decline is associated with increased risk of mortality in geriatric patients. Assessment of activities of daily living (ADL) with the Barthel Index (BI) at admission was studied as a predictor of survival in older patients admitted to an acute geriatric unit.

Methods: All first admissions of patients with age $>65$ years between January $1^{\text {st }} 2005$ and December $31^{\text {st }} 2009$ were included. Data on Bl, sex, age, and discharge diagnoses were retrieved from the hospital patient administrative system, and data on survival until September $6^{\text {th }} 2010$ were retrieved from the Civil Personal Registry. Co-morbidity was measured with Charlson Co-morbidity Index (CCI). Patients were followed until death or end of study.

Results: 5,087 patients were included, 1,852 (36.4\%) men and 3,235 (63.6\%) women with mean age 81.8 (6.8) and 83.9 (7.0) years respectively. The median [IQR] length of stay was 8 days, the median follow up [IQR] 1.4 [0.3; 2.8] years and in hospital mortality $8.2 \%$. Mortality was greater in men than in women with median survival (95\%-Cl) 1.3 $(1.2-1.5)$ years and $2.2(2.1-2.4)$ years respectively $(p<0.001)$. The median survivals $(95 \%-\mathrm{Cl})$ stratified on $\mathrm{Bl}$ groups in men $(n=1,653)$ and women $(n=2,874)$ respectively were: Bl 80-100: 2.6 (1.9-3.1) years and 4.5 (3.9-5.4) years; BI 5079: 1.7 (1.5-2.1) years and 3.1 (2.7-3.5) years; BI 25-49: 1.5 (1.3-1.9) years and 1.9 (1.5-2.2) years and BI 0-24: 0.5 (0.3-0.7) years and 0.8 (0.6-0.9) years. In multivariate logistic regression analysis with BI 80-100 as baseline and controlling for significant covariates (sex, age, CCl, and diseases of cancer, haematology, cardiovascular, respiratory, infectious and bone and connective tissues) the odds ratios for 3 and 12 months survival $(95 \%-\mathrm{Cl})$ decreased with declining $\mathrm{BI}: \mathrm{BI}$ 50-79: $0.74(0.55-0.99)(p<0.05)$ and $0,80(0.65-0.97)(p<0.05) ; B I 25-49: 0.44(0.33-0.59)(p<0.001)$ and $0.55(0.45-0.68)$ $(p<0.001)$; and BI 0-24: $0.18(0.14-0.24)(p<0.001)$ and $0.29(0.24-0.35)(p<0.001)$ respectively.
\end{abstract}

Conclusion: $\mathrm{Bl}$ is a strong independent predictor of survival in older patients admitted to an acute geriatric unit. These data suggest that assessment of ADL may have a potential role in decision making for the clinical management of frail geriatric inpatients.

Keywords: ADL, Barthel Index, Charlson Index, Co-morbidity, Elderly, Functional assessment, Geriatric, Mortality, Survival

\footnotetext{
* Correspondence: lars.matzen@ouh.regionsyddanmark.dk

'Department of Geriatric Medicine, Odense University Hospital, DK-5000,

Odense C, Denmark

${ }^{2}$ University of Southern Denmark, Odense, Denmark

Full list of author information is available at the end of the article
} 


\section{Background}

The combination of acute and chronic diseases in the ageing individual often results in disabilities and limitations in activities of daily living (ADL) [1]. Different co-morbidity indexes can measure this heterogeneity and be used in prognosis estimation [2]. However, they are time consuming in practice and difficult to implement in daily use.

Functional limitations are associated with mortality in patients with hip fractures [3], pulmonary infections [4,5] and acute medical patients [6,7]. The Barthel Index (BI) [8] is an easy to use instrument originally developed to measure ADL in stroke patients, but subsequently its use has been extended into geriatric patients [9]. In Denmark BI is the official ADL tool included in the Diagnosis Related Groups for hospitals reimbursement of geriatric patients.

The health care system in the western world will in the years to come face an increasing number of older people with chronic diseases [10], and simple and easy to use instruments to predict prognosis may be helpful in planning the optimal management of geriatric patients, both to the benefit of the individual patient but also to the benefit of health care expenses. The aim of this study was to evaluate whether the routine use of BI could be included as a prognosis indicator in terms of survival in geriatric patients.

\section{Methods}

\section{Data collection}

Between January $1^{\text {st }} 2005$ and December $31^{\text {st }} 2009$ 7,723 patients were admitted to the Department of Geriatric Medicine at Odense University Hospital. Patients first admission with a length of stay $>$ one day and age $>65$ years were included in this study $(n=5,087)$. The hospital serves a population of about 300.000 citizens. Up to June $1^{\text {st }} 2008$ patients were referred directly to the geriatric wards, thereafter admitted to the acute medical ward and within 24 hours transferred to the geriatric wards, based on either daytime assessment by geriatricians or written algorithms (acute medical problems, multi co-morbidities and functional limitations).

In Denmark every citizen at birth or immigration is given a unique Civil Personal Registry Code which will identify the person in every contact with the health care system. From the hospital Patients Administrative System, data on sex, age, date of admission and diagnoses were collected. Patients were followed until death or end of study at September $6^{\text {th }} 2010$. Data on survivals were retrieved from the Civil Personal Registry, and survival times from date of first admission were calculated.

Diagnoses were grouped according to the International Classification of Diseases $10^{\text {th }}$ revision (ICD-10) in primary diagnoses describing the leading disease during hospital stay, secondary diagnoses describing other important diseases and the combination of either primaryor secondary-diagnoses (Appendix 1).

\section{Co-morbidity index}

Co-morbidity was measured with the Charlson Comorbidity Index (CCI) which was calculated from ICD-10 diagnoses retrieved from the Patient Administrative System (Appendix 2) [11,12]. The validity of the calculated CCI was tested by one of the authors (DJ), who identified all existing diagnoses by reviewing a sample of 95 patients records. Using this as the references, the ICD-10 diagnoses from the Patient Administrative System identified 82\% of patients with chronic pulmonary diseases, $78 \%$ with congestive heart diseases, $71 \%$ with dementia, $67 \%$ with upper gastrointestinal ulcer diseases, $62 \%$ with cerebrovascular diseases, $52 \%$ with ischaemic heart diseases, $47 \%$ with diabetes and $42 \%$ with present or former malignancies. The correlation coefficient between the review and the CCI calculated from ICD-10 diagnoses was 0.67 (Spearmann, $\mathrm{p}<0.001)$.

\section{Activities of daily living}

ADL was measured with BI [8] and scored by nurses or nursing assistants within 48 hours after admission on the basis of their observations and/or self-report from patients and/or proxies. The $\mathrm{BI}$ is a sum score of $10 \mathrm{ADL}$ items: mobility, stair climbing, transfer, feeding, bathing, toilet use, bowel function, bladder function and grooming with a range from 0 (dependent) to 100 (independent). Individual BI had been measured in 4,527 (89\%) patients and scorings were grouped in four ADL groups (ICD-10 diagnoses): "Very low ADL": BI: 0-24 (R673), "Low ADL": BI: 25-49 (R672), "Moderate reduced ADL": BI: 50-79(R671) and "Independent ADL": BI: 80-100(R670). BI is part of the Danish Diagnosis Related Group algorithm for geriatric patients including 1): Multi-morbidity defined as diseases within more than two ICD-10 main groups, 2): ADL at admission measured with $\mathrm{BI}$, and 3): Interventions for rehabilitation.

\section{Statistical analysis}

Basic data handling with creation of ICD-10 groups and CCI were performed using SPSS, version 18.0. Variables with normal distributions are reported as mean (SD). Variables not normally distributed are reported as median [percentiles 25\% and 75\%]. Kaplan-Meier survival analysis and logistic regression analysis using STATA version 12.0. Median survivals with 95\% confidence interval (95\%-CI) are estimated from Kaplan-Meier plots. In the logistic regression analysis the dependent variables were survival $<=3$ months and $<=12$ months from admission. Odds ratios (95\%-CI) from multivariate analysis are reported. All independent variables (sex, age, CCI, ICD-10 diagnosis) were included in the analysis and in successive steps removed at $\mathrm{p}>0.05$. ICD-10 diagnoses were included both as single primary- and secondary-diagnosis and as the combinations of. 
The study was approved by the Danish Data Protection Agency (number: 2010-41-5195). According to the Danish Law on Medical Ethics informed consent was not needed as only existing registry data from patient records, Patient Administrative System and Civil Personal Registry were used.

\section{Results}

5,087 patients were included, 1,852 (36.4\%) men and $3,235(63.6 \%)$ women with mean age (SD) 81.8 (6.8) and 83.9 (7.0) years respectively (Table 1 ). The median [IQR] length of stay was $8[5 ; 13]$ days.

Follow up after first admission was median [IQR] 1.4 [0.3; 2.8$]$ years corresponding to 8,960 patients years. Overall mortality in hospital was $8.2 \%(417 / 5,087)$ and during follow up 54,8\% (2,785/5,087) (Table 1). Except for Diseases of Bone and Connective Tissue most diseases were more common in men, who had a CCI above 2 in $42.8 \%$ of men as compared to $31.1 \%$ of women (Table 1 ).

In 560 patients (199 men and 361 women) BI had not been measured. These patients did not differ according to sex, age, CCI or length of stay from the 4,527 (89\%) patients [1,653 (36.5\%) men and 2,874 (63,5\%) women] included in the survival and logistic regression analyses.

Mortality was greater in men than in women with survival median (95\%-CI) $1.3(1.2-1.5)$ years and 2.2 (2.12.4 ) years respectively (Kaplan-Meier, $\mathrm{p}<0.001$ ). In both sexes survival were associated with BI (Figures 1 and 2). The median (95\%-CI) survivals stratified on BI groups in men and women respectively were: BI 80-100: 2.6 (1.9$3.1)$ years and 4.5 (3.9-5.4) years; BI 50-79: 1.7 (1.5-2.1) years and 3.1 (2.7-3.5) years; BI 25-49: 1.5 (1.3-1.9) years and $1.9(1.5-2.2)$ years and BI 0-24: $0.5(0.3-0.7)$ years and $0.8(0.6-0.9)$ years.

Table 1 Basic data on 5,087 patients admitted to a geriatric department

\begin{tabular}{|c|c|c|c|}
\hline & Male $(n=1,852)$ & Female $(n=3,235)$ & \\
\hline Age, mean (SD) & $81.8(6.8)$ & $83.9(7.0)$ & $<0.001$ \\
\hline Length of stay, median [IQR] & $8[5 ; 14]$ & $8[5 ; 13]$ & n.s. \\
\hline \multicolumn{4}{|l|}{ Barthel-Index } \\
\hline $80-100$ & $296(17.9 \%)$ & $523(18.2 \%)$ & \multirow[t]{4}{*}{ n.s. } \\
\hline $50-79$ & $452(27.3 \%)$ & $856(29.8 \%)$ & \\
\hline $25-49$ & $363(22.0 \%)$ & $643(22.4 \%)$ & \\
\hline $0-24$ & $542(32.8 \%)$ & $852(29.7 \%)$ & \\
\hline \multicolumn{4}{|l|}{ Survival status } \\
\hline Alive $6^{\text {th }}$-september 2010 & $563(30.4 \%)$ & $1,322(40.9 \%)$ & \multirow[t]{3}{*}{$<0.001$} \\
\hline Discharged and dead before $6^{\text {th }}$ sept. 2010 & $1,115(60.2 \%)$ & $1,670(51.6 \%)$ & \\
\hline Dead in hospital & $174(9.4 \%)$ & $243(7.5 \%)$ & \\
\hline \multicolumn{4}{|l|}{ Charlson Comorbidity Index } \\
\hline 0 & $443(23.9 \%)$ & $1,025(31.7 \%)$ & \multirow[t]{4}{*}{$<0.001$} \\
\hline 1 & $617(33.3 \%)$ & $1,205(37.3 \%)$ & \\
\hline 2 & $429(23.2 \%)$ & $621(19.2 \%)$ & \\
\hline$>=3$ & $363(19.6 \%)$ & $384(11.9 \%)$ & \\
\hline \multicolumn{4}{|l|}{ ICD-diagnosis group } \\
\hline Infectious diseases (A00 - B99) & $134(7.2 \%)$ & $256(7.9 \%)$ & n.s. \\
\hline Any cancer (C00 - C75) & $372(20.1 \%)$ & $485(15.0 \%)$ & $<0.001$ \\
\hline Haematological disease (D50 - D89) & $322(17.4 \%)$ & $465(14.4 \%)$ & $<0.01$ \\
\hline Endocrine diseases (E00 - E99) & $636(34.3 \%)$ & $1,317(40.7 \%)$ & $<0.001$ \\
\hline Psychiatric diseases (F00 - F99) & $488(26.4 \%)$ & $822(25.4 \%)$ & n.s. \\
\hline Neurologic diseases (G00 - G99) & $160(8.6 \%)$ & $204(6.3 \%)$ & $<0.01$ \\
\hline Cardiovascular diseases $(100-199)$ & $1,242(67.1 \%)$ & $2,066(63.9 \%)$ & $<0.05$ \\
\hline Respiratory diseases (J00 - J99) & 738 (39.8\%) & $1,007(31.1 \%)$ & $<0.001$ \\
\hline Gastrointestinal diseases (K00 - K93) & $291(15.7 \%)$ & $527(16.3 \%)$ & n.s. \\
\hline Bone and Connective tissue (M00 - M99) & $271(14.6 \%)$ & $912(28.2 \%)$ & $<0.001$ \\
\hline Urologic diseases (N00 - N99) & $532(28.7 \%)$ & $682(21.1 \%)$ & $<0.001$ \\
\hline Number of ICD-diagnosis (mean, SD) & $4.4(1.4)$ & $4.3(1.4)$ & n.s. \\
\hline
\end{tabular}




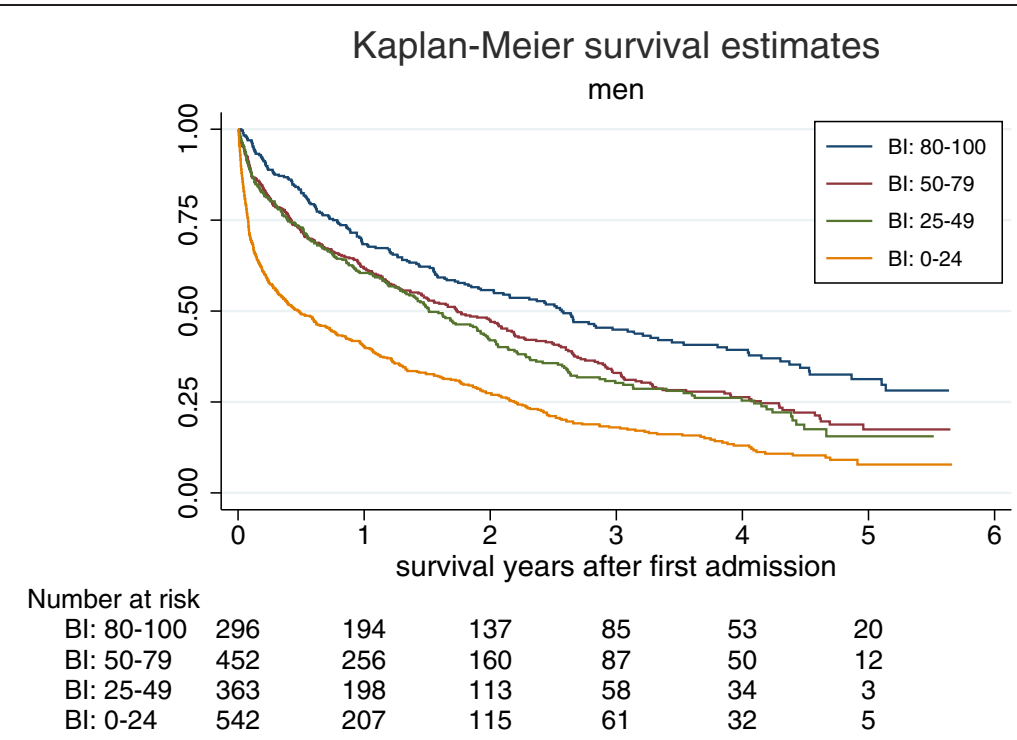

Figure 1 Kaplan-Meier survival estimates in men stratified on Barthel Index (BI) measured at admission. Bl: 80-100 (blue), 50-79 (red), 2549 (green), 0-24 (yellow).

Survival 3 and 12 months after admission decreased with decreasing BI. With BI 80-100 as baseline the unadjusted OR (95\%-CI) of surviving 3 and 12 month decreased from BI 50-79: $0.65(0.49-0.86)(\mathrm{p}<0.01)$ and $0.73(0.60-0.88)(\mathrm{p}<0.01)$ respectively, BI 25-49: 0.40 $(0.30-0.53)(\mathrm{p}<0.001)$ and $0.49(0.400 .60)(\mathrm{p}<0.001)$ respectively to BI $0-24: 0.16 \quad(0.120 .21) \quad(\mathrm{p}<0.001)$ and $0.25(0.210 .30) \quad(\mathrm{p}<0.001)$ respectively. In the multivariate logistic regression analysis the association between decreasing OR's of survival and decreasing BI were still present (Table 2). Other independent variables decreasing 3 month survivals were increasing age, increasing CCI, diagnoses of cancer, cardiovascular and respiratory diseases. Independent variables decreasing 12 months survival were male sex, diagnoses of cancer, diagnoses of haematology and respiratory diseases (Table 2). In this group of patients infectious diseases and diseases of bone and connective tissues were associated with increased 3 and 12 month survivals (Table 2).

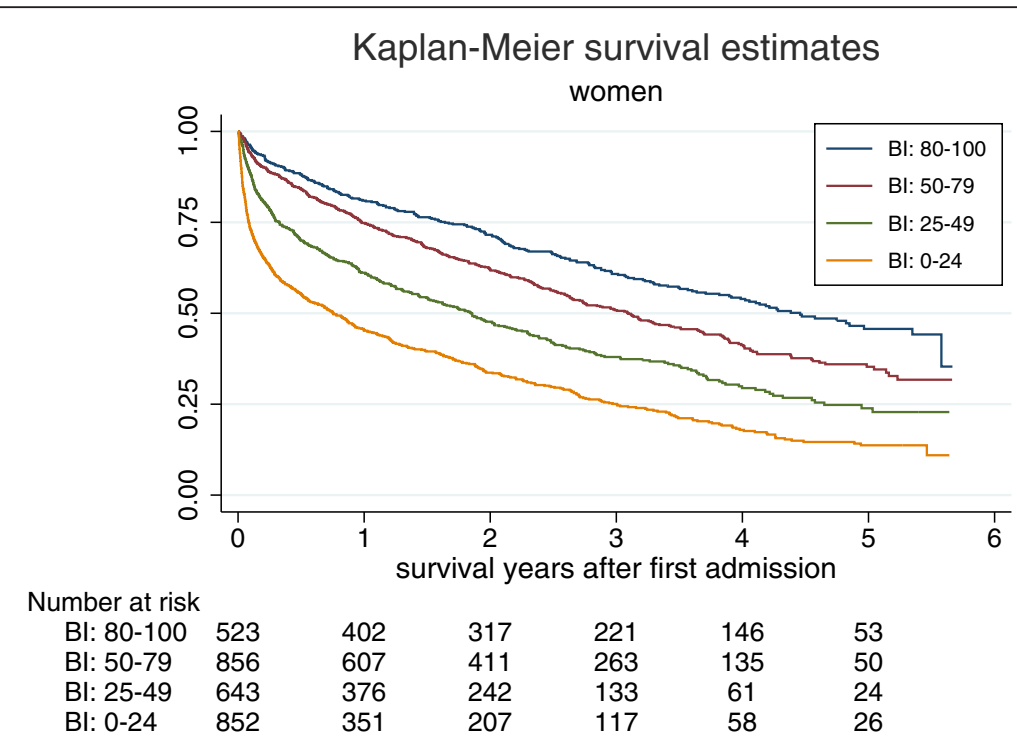

Figure 2 Kaplan-Meier survival estimates in women stratified on Barthel Index (BI) measured at admission. BI: 80-100 (blue), 50-79 (red), 25-49 (green), 0-24 (yellow). 
Table 2 Multivariate logistic regression analysis: Odds Ratio (OR) and 95\% confidence interval (95\%-CI) of 3 and 12 month survival after date of admission in geriatric patients $(n=4,527)$

\begin{tabular}{|c|c|c|c|c|c|}
\hline & & \multicolumn{2}{|c|}{ Survival 3 month } & \multicolumn{2}{|c|}{ Survival 12 month } \\
\hline & & OR & $95 \%-\mathrm{Cl}$ & OR & $95 \%-\mathrm{Cl}$ \\
\hline \multirow[t]{4}{*}{ Barthel Index } & Baseline: 80-100 & & & & \\
\hline & $50-79$ & 0.74 & $(0.55-0.99)^{*}$ & 0.80 & $(0.65-0.97)^{*}$ \\
\hline & $25-49$ & 0.44 & $(0.33-0.59)^{* * *}$ & 0.55 & $(0.45-0.68)^{* * *}$ \\
\hline & $0-24$ & 0.18 & $(0.14-0.24)^{* * *}$ & 0.29 & $(0.24-0.35)^{* * *}$ \\
\hline Sex & Male (0), Female (1) & 1.11 & $(0.95-1.31)$ n.s. & 1.27 & $(1.11-1.45)^{* * *}$ \\
\hline Age & years & 0.96 & $(0.95-0.97)^{* * *}$ & 0.97 & $(0.96-0.98)^{* * *}$ \\
\hline \multirow[t]{4}{*}{ Charlson Comorbidity Index } & Baseline: 0 & & & & \\
\hline & 1 & 0.96 & $(0.78-1.19)$ n.s. & 0.83 & $(0.71-0.98)^{*}$ \\
\hline & 2 & 0.62 & $(0.48-0.78)^{* * *}$ & 0.63 & $(0.52-0.77)^{* * *}$ \\
\hline & $>=3$ & 0.53 & $(0.40-0.70)^{* * *}$ & 0.51 & $(0.40-0.64)^{* * *}$ \\
\hline \multicolumn{6}{|l|}{ ICD-10 diagnoses } \\
\hline Cancer & Diagnoses (C00-D48) & 0.33 & $(0.25-0.42)^{* * *}$ & 0.38 & $(0.29-0.49)^{* * *}$ \\
\hline Cardiovascular diseases & A-diagnoses (100-199) & 0.62 & $(0.50-0.77)^{* * *}$ & & \\
\hline Haematology & Diagnoses (D50-D89) & & & 0.77 & $(0.65-0.92)^{* *}$ \\
\hline Respiratory Diseases & Diagnoses (J00-J99) & 0.59 & $(0.50-0.69)^{* * *}$ & 0.67 & $(0.59-0.77)^{* * *}$ \\
\hline Infectious Diseases & Diagnoses (A00-B99) & 2.59 & $(1.85-3.64)^{* * *}$ & 2.24 & $(1.78-3.36)^{* * *}$ \\
\hline Bone and Connective Tissue Diseases & Diagnoses (M00-M79, M86-M99) & 1.54 & $(1.26-1.87)^{* * *}$ & 1.24 & $(1.07-1.45)^{* *}$ \\
\hline
\end{tabular}

***: $p<0.001,{ }^{* *}: p<0.01,{ }^{*} p<0.05$.

A-diagnosis: Primary ICD-10 discharge diagnosis.

B-diagnosis: Secondary ICD-10 discharge diagnosis.

Independent variables: activities of daily living (ADL-group) measured with Barthel-Index, sex, age, comorbidity measured by Charlson Comorbidity Index and ICD-10 diagnoses.

\section{Discussion}

The main finding in this study was the strong and independent association between ADL function and survival in geriatric patients. The BI could differentiate between groups with a good or bad prognosis in terms of survival. The probability of being alive 3 month after admission was $75 \%$ with BI $50-79,44 \%$ with BI $26-49$ and only $18 \%$ with BI 0-25. The corresponding figures for being alive 12 month after admission were $80 \%, 54 \%$ and $28 \%$. However, as shown in Figures 1 and 2 the prognosis in an individual patient would still be difficult to estimate and even in patients with BI below 25, more than $25 \%$ of male and female patients were alive after 2.2 and 3.0 years respectively. As shown in the Kaplan-Meier graphs, the four BI groups discriminated better in women than in men. In the latter, the survivals of men in the BI 50-79 and BI 25-49 were the same.

The patients in this study were a selected cohort of older medical patients. However, they were representative of a typical case-mix population admitted to an acute geriatric department [13-17]. The strength of this study was the inclusion of 4,527 patients in the survival analysis and the ability to collect data from the Danish national databases of diagnoses and mortality. A limitation is that the data were generated in the clinical setting with associated reporting uncertainties in diagnoses.
The associations between functional status or frailty, multi-morbidity and mortality have been described previously in study settings [4-6,18,19]. Walter et al. [20] found that functional status at discharge, male sex, cancer, hearth diseases, creatinine and albumin at admission were predictive of one year survival. In a prospective study of 463 acute medical patients with a median CCI of 2.1, Buurman at al. [6] found that the risk of mortality was associated with four clinical variables - functional level measured with BI, comorbidity, malignancy and serum urea nitrogen level. Raineri et al [4] found in a prospective study of 244 patients with mean age 81.7 years and acute exacerbations in COPD, that risk factors for 6 month mortality were BMI, BI at discharge and morbidity measured with Apache II. Torres et al. [5] found in elderly patients with pneumonia, that high BI was related to reduced 30-day and 18 month mortalities. Our results were consistent with these studies showing the same associations between mortality and functional status, comorbidity and single diseases of cancer, cardiovascular, respiratory and haematology. The positive odds ratios of infectious diseases and diseases of bone and connective tissues on both 3 and 12 month survivals indicated that the former normally were cured and the latter might be troublesome but not lethal.

Male sex, age and co-morbidity measured with CCI were associated, independently of functional status, with 
decreased survival and the survival odds ratios decreased with increasing CCI. The association between co-morbidity and survival was also found previously in a study on $1,567,659$ admissions [21], but in contrast to our study data on functional status was lacking.

BI scorings were performed by nurses or nursing assistants and the methods used were observations of patient performances, interview with patients and/or proxies. BI data had been reported in $89 \%$ of our patients and as part of the DRG reimbursement the nursing staff were instructed to accurately score the $\mathrm{BI}$, when receiving new patients in the wards. All new staff members were instructed in BI scoring at employment. Although we had no data on the reliability of this method in our department, others have found acceptable interrater reliability of BI scoring done by nonclinical assistants [22] and when scoring was performed by different observers as in our department [9].

In this study we had data only on the four ADL diagnoses groups and not on the ten BI sub-items. Therefore, it was not possible to ascertain whether some of the items had greater impact than the others. The study was based on data obtained in clinical setting, and imprecision in the BI sum score might influence the allocation to ADL diagnoses groups, but probably not the strong association between BI and survival.

In a study using ICD-10 diagnoses from the Patient Administrative System some uncertainties in diagnosis reporting are inevitable. The meticulous review of 95 patient records gave a higher $\mathrm{CCI}$ than the one created from ICD-10 diagnoses. However, the coefficient of correlation was 0.67 and ICD-10 calculated CCI was accepted as a proxy for co-morbidity. The validity of primary diagnosis in the Danish Registry of Discharge Diagnosis has been found to be high [12].

\section{Conclusion}

Functional status at admission in combination with demographic factors and comorbidities could potentially be used in the decision making process on further management of geriatric patients. Acute medical conditions should of course be treated without hesitation. However knowledge of functional status and its predicting ability in terms of survival may influence decisions on factors such as the extent of invasive investigations, treatments associated with significant risk, and adding to the polypharmacy burden of elderly patients. These issues require further exploration.

\section{Appendix 1}

Grouping of ICD-10 diagnosis: Infectious Diseases (A00B99), Cancer (C00-D48), Haematology (D50-D89), Endocrine (E00-E99), Psychiatric including Dementia (F00F99, G300-G309), Neurology (G00-G30, G31-G99),
Cardiovascular Diseases (I00-199), Respiratory Diseases (J00-J99), Gastrointestinal Diseases (K00-K93), Dermatology (L00-L99), Bone and Connective Tissue Diseases (M00-M79, M86-M99) and Urology (N00-N99).

\section{Appendix 2}

Charlson Index (CCI) calculated from Patient Administrative System ICD-10 diagnoses (rank; ICD-10 number): Ischaemic Heart Diseases and Myocardial Infarction (1; I21, I22, I23, I25), Congestive Heart Failure (1; I50, I110, I130 I132), Peripheral Vascular Diseases (1; I70, I71, I72, I73, I74, I77), Cerebrovascular Diseases (1; I60-I69, G45, G46), Dementia (1; F00-F03, F051, G30), Chronic Pulmonary Diseases (1; J40-J47, J60-J67, J684, J70.1, J703, J84.1, J920, J961, J982, J983), Diabetes uncomplicated (1; E10, E101, E109, E110, E111, E119, E140, E141, E149), Connective Tissue Diseases (1; M05, M06, M08, M09, M30-M36, D86), Upper Gastro-intestinal and Ulcer Diseases (1; K221, K25-K28), Mild Liver Diseases (1; B18, K70-K703, K709, K71, K73, K74, K76), Hemiplegia (2; G81, G82), Moderate/severe Renal Diseases (2; I12, I13, N00-N05, N07, N11, N14, N17-N19, Q61), Diabetes Mellitus with Chronic Complications (2; E102-E108, E112-E118, E142E148), Leucaemia (2; C91-C95), Lymphoma (2; C81-C85, C88, C90, C96), Moderate/severe Liver Diseases (2; B150, B160, B162, B190, K704, K72, K766, I85), Metastatic solid Cancer (6; C76-C80) and AIDS (6; B21-B24).

\section{Competing interest \\ Lars Erik Matzen: None \\ Ditte Beck Jepsen: None \\ Jesper Ryg: None \\ Tahir Masud: None}

\section{Authors' contributions}

LEM, Head of Department, Associate Professor: Conception and design, acquisition of data, data analysis and interpretation of data, drafting manuscript, critical revising manuscript, final approval. DBJ, medical student: Validation of diagnosis and Charlson Index, final approval. JR, Post-Doc, Ph.D.: Conception and design, interpretation of data, critical revising manuscript for intellectual content, final approval. TM, Professor, Ph.D.: Conception and design, interpretation of data, critical revising manuscript for intellectual content, final approval. All authors read and approved the final manuscript.

\section{Author details}

${ }^{1}$ Department of Geriatric Medicine, Odense University Hospital, DK-5000, Odense C, Denmark. 'University of Southern Denmark, Odense, Denmark. ${ }^{3}$ Department of Geriatric Medicine, Nottingham University Hospital, Nottingham, UK.

Received: 20 December 2011 Accepted: 15 June 2012 Published: 25 June 2012

\section{References}

1. Verbrugge LM, Jette AM: The disablement process. Soc Sci Med 1994, 38:1-14.

2. Zekry D, Loures Valle BH, Lardi C, Graf C, Michel JP, Gold G, Krause KH, Herrmann FR: Geriatrics index of comorbidity was the most accurate predictor of death in geriatric hospital among six comorbidity scores. J Clin Epidemiol 2010, 63:1036-1044.

3. Formiga F, Chivite D, Sole A, Manito N, Ramon JM, Pujol R: Functional outcomes of elderly patients after the first hospital admission for 
decompensated heart failure (HF). A prospective study. Arch Gerontol Geriatr 2006, 43:175-185.

4. Ranieri P, Bianchetti A, Margiotta A, Virgillo A, Clini EM, Trabucchi M: Predictors of 6-month mortality in elderly patients with mild chronic obstructive pulmonary disease discharged from a medical ward after acute nonacidotic exacerbation. J Am Geriatr Soc 2008, 56:909-913.

5. Torres OH, Munoz J, Ruiz D, Ris J, Gich I, Coma E, Gurgui M, Vazquez G: Outcome predictors of pneumonia in elderly patients: importance of functional assessment. J Am Geriatr Soc 2004, 52:1603-1609.

6. Buurman BM, van Munster BC, Korevaar JC, Abu-Hanna A, Levi M, de Rooij SE: Prognostication in acutely admitted older patients by nurses and physicians. J Gen Intern Med 2008, 23:1883-1889.

7. Espaulella J, Arnau A, Cubi D, Amblas J, Yanez A: Time-dependent prognostic factors of 6-month mortality in frail elderly patients admitted to post-acute care. Age Ageing 2007, 36:407-413.

8. Mahoney Fl, Barthel DW: Functional Evaluation: The Barhel Index. Md State Med J 1965, 14:61-65. 61-65.

9. Sainsbury A, Seebass G, Bansal A, Young JB: Reliability of the Barthel Index when used with older people. Age Ageing 2005, 34:228-232.

10. Christensen K, Doblhammer G, Rau R, Vaupel JW: Ageing populations: the challenges ahead. Lancet 2009, 374:1196-1208.

11. Charlson ME, Pompei P, Ales KL, Mackenzie CR: A new method of classifying prognostic comorbidity in longitudinal studies: Development and validation. J Chron Dis 1987, 40:373-383.

12. Thygesen SK, Christiansen CF, Christensen S, Lash TL, Sorensen HT: The predictive value of ICD-10 diagnostic coding used to assess Charlson comorbidity index conditions in the population-based Danish National Registry of Patients. BMC Med Res Methodol 2011, 11:83-83.

13. Saltvedt I, Saltnes T, Mo ES, Fayers P, Kaasa S, Sletvold O: Acute geriatric intervention increases the number of patients able to live at home. A prospective randomized study. Aging Clin Exp Res 2004, 16:300-306.

14. Baztan JJ, Suarez-Garcia FM, Lopez-Arrieta J, Rodriguez-Manas L, Rodriguez-Artalejo F: Effectiveness of acute geriatric units on functional decline, living at home, and case fatality among older patients admitted to hospital for acute medical disorders: meta-analysis. BMJ 2009, 338:b50.

15. Asplund K, Gustafson Y, Jacobsson C, Bucht G, Wahlin A, Peterson J, Blom JO, Angquist KA: Geriatric-based versus general wards for older acute medical patients: a randomized comparison of outcomes and use of resources. J Am Geriatr Soc 2000, 48:1381-1388.

16. Counsell SR, Holder CM, Liebenauer LL, Palmer RM, Fortinsky RH, Kresevic DM, Quinn LM, Allen KR, Covinsky KE, Landefeld CS: Effects of a multicomponent intervention on functional outcomes and process of care in hospitalized older patients: a randomized controlled trial of Acute Care for Elders (ACE) in a community hospital. J Am Geriatr Soc 2000, 48:1572-1581.

17. Landefeld CS, Palmer RM, Kresevic DM, Fortinsky RH, Kowal J: A randomized trial of care in a hospital medical unit especially designed to improve the functional outcomes of acutely ill older patients. N Engl J Med 1995, 332:1338-1344.

18. Salvi F, Miller MD, Grilli A, Giorgi R, Towers AL, Morichi V, Spazzafumo L, Mancinelli L, Espinosa E, Rappelli A, et al: A Manual of Guidelines to Score the Modified Cumulative Illness Rating Scale and Its Validation in Acute Hospitalized Elderly Patients. J Am Geriatr Soc 2008, 56:1926-1931.

19. Zekry D, Valle BH, Michel JP, Esposito F, Gold G, Krause KH, Herrmann FR: Prospective comparison of six co-morbidity indices as predictors of 5 years post hospital discharge survival in the elderly. Rejuvenation Res 2010, 13:675-682.

20. Walter LC, Brand R, Counsell SR, Palmer RM, Landefeld CS, Fortinsky RH, Covinsky KE: Development and Validation of a Prognostic Index for 1-Year Mortality in Older Adults After Hospitalization. JAMA 2001, 285:2987-2994.

21. Barba R, Martinez JM, Zapatero A, Plaza S, Losa JE, Canora J, Perez A, de Garcia CG: Mortality and complications in very old patients $(90+)$ admitted to departments of internal medicine in Spain. Eur J Intern Med 2011, 22:49-52.

22. Richards SH, Peters TJ, Coast J, Gunnell DJ, Darlow MA, Pounsford J: Inter-rater reliability of the Barthel ADL index: how does a researcher compare to a nurse? Clin Rehabil 2000, 14:72-78.

doi:10.1186/1471-2318-12-32

Cite this article as: Matzen et al:: Functional level at admission is a predictor of survival in older patients admitted to an acute geriatric unit. BMC Geriatrics 2012 12:32.

\section{Submit your next manuscript to BioMed Central and take full advantage of:}

- Convenient online submission

- Thorough peer review

- No space constraints or color figure charges

- Immediate publication on acceptance

- Inclusion in PubMed, CAS, Scopus and Google Scholar

- Research which is freely available for redistribution 